\title{
RECAPITULATIO \\ SIMPUL KRISTOLOGI IRENEUS DARI LYON DALAM ADVERSUS HAERESES
}

\author{
Sihol Situmorang dan Angelo Bonardo Purba*
}

\begin{abstract}
Abstrak
Gereja mengimani Yesus Kristus sungguh Allah dan sungguh manusia. Untuk sampai pada perumusan pokok iman ini, Gereja dihadapkan pada dua aliran yang bertolak belakang. Pertama, aliran yang menekankan kemanusiaan Yesus dengan menolak ketuhanan-Nya. Kedua, aliran yang mengagungkan ketuhanan-Nya dengan memungkiri kemanusiaan-Nya. Dalam konteks polemik dengan aliran sesat tersebut, Ireneus membela iman Gereja. Ia merumuskan iman akan Yesus Kristus dengan kata recapitulatio. Menurut Ireneus, tujuan kehadiran Yesus di dunia ini adalah untuk mempersatukan semua ciptaan ke dalam diri-Nya dan mengangkat manusia menjadi Anak Allah. Artinya, kristologi Ireneus adalah soteriologi.
\end{abstract}

Kata-kata kunci: Yesus Kristus, inkarnasi, recapitulatio, oikonomia, gnostisisme, heresi, keselamatan.

\section{Pengantar}

Upaya untuk merumuskan doktrin iman yang benar mengenai Yesus Kristus, sebagaimana juga tentang Trinitas, melewati tahapan yang panjang dan rumit, khususnya akibat munculnya aneka ajaran sesat. Situasi semakin sulit, karena instansi yang berwenang menentukan ajaran yang berlaku umum belum ada. Rumusan iman yang benar dicapai setelah melangsungkan pelbagai sinode di tingkat keuskupan dan konsili pada level Gereja unieversal. Seorang tokoh yang memberi kontribusi penting dalam perumusan iman akan Yesus Kristus adalah Ireneus dari Lyon. Pada masa Ireneus, Gereja berjuang membela imannya di hadapan pelbagai tuduhan dari pihak pemerintah Romawi dan sejumlah aliran

\footnotetext{
* Sihol Situmorang, lisensiat dalam bidang Theologi Patristik; lulusan Universitas Lateranensis, Roma; dosen Theologi pada Fakultas Filsafat Unika St. Thomas, Sumatera Utara; Angelo Bonardo Purba, mahasiswa pada Fakultas Filsafat Unika St. Thomas, Sumatera Utara.
} 
heretik. Ireneus berupaya mencapai perumusan iman akan Yesus Kristus sesuai dengan tradisi apostolik, yang dirangkum dengan istilah recapitulatio.

\section{Riwayat Hidup dan Karya-karya Ireneus}

Ireneus, murid Polikarpus, lahir di Smyrna-Asia Kecil antara tahun 130-140. Ia ditahbiskan menjadi imam dan kemudian dipilih menjadi uskup di Lyon sekitar tahun 177/178 menggantikan Pothinus yang wafat sebagai martir. Ireneus meninggal sebagai martir sekitar tahun 200. Karya utama Ireneus adalah Adversus Haereses dan Epideixis. Adversus Haereses memuat upaya penelanjangan dan bantahan terhadap gnosis palsu. Buku ini ditulis dalam bahasa Yunani, terdiri dari lima buku. Buku I memuat kepalsuan doktrin gnosis. Dalam buku II, Ireneus menjelaskan ajaran iman untuk melawan ajaran heretik tersebut. Dalam buku III dan IV, Ireneus menjelaskan doktrin Gereja mengenai Allah. Ia membangun kriteria teologis dan ekklesiastik suatu kebenaran, yaitu canon veritatis, regula fidei dan traditio apostolica. Buku $\mathrm{V}$ berbicara mengenai kebangkitan badan. Sementara Epideixis lebih merupakan sebuah tulisan apologetik perihal uraian singkat atas dasar-dasar doktrin iman Kristiani. ${ }^{1}$

\section{Konteks Sosial-Politik-Religius}

Pada masa Ireneus, banyak orang Kristen yang ditangkap, diadili, disiksa bahkan dibunuh dengan pelbagai alasan. Pertama, orang Kristen dituduh melakukan praktik magis. Kedua, orang Kristen dituduh ateis, karena menolak membawa persembahan kepada dewa-dewi bangsa Romawi. Ketiga, orang Kristen dituduh melakukan tindakan amoral.

\footnotetext{
1 Antonio Orbe, "Irenaeus" dalam Angelo Di Bernardino (ed.), Encyclopedia of the Early Church (Cambridge: Jame Clarke and Co., 1992), hlm. 413-416; Quasten, Johannes. Patrology Vol. I (Notre Dame: Christian Classics, 1960), hlm. 288-289; Hubertus R. Drobner, Patrologia, judul asli Lehrbuch der Patrologia, diterjemahkan oleh Paolo Stefano dan Francesco Sirleto (Casale Monferrato: Edizione Piemme, 1998), hlm. 179-185; Alois Grillmeier, Gesù il Cristo nella fede della Chiesa vol. 1, judul asli Jesus der Christus im Glauben der Kirche, diterjemahkan oleh Enrico Norelli e Samuele Olivieri (Brescia: Paideia Editrice) hlm. 278280.
} 
Penganiayaan semakin hebat dengan dikeluarkannya Trajan's Rescript ${ }^{2}$ oleh Kaisar Trayanus, yang berkuasa dari tahun 98-117. Dengan itu, penganiayaan terhadap orang Kristen memiliki legalitas yuridis. Pada zaman ini, banyak orang Kristen yang wafat sebagai martir. ${ }^{3}$

Ketika kekristenan semakin populer, muncul banyak kelompok, dengan latar belakang dan tradisi agama yang berbeda, seperti gnostisisme $^{4}$, marcionisme ${ }^{5}$, montanisme ${ }^{6}$, monarkianisme ${ }^{7}$ dan yang lain. Para pencetus aliran tersebut ingin memberikan pengaruh bagi

2 Trajan's Rescript adalah suatu peraturan yang dikeluarkan oleh Kaisar Trayanus untuk menghukum orang Kristen. Reskrip ini menjelaskan beberapa alasan mengapa orang Kristen dianiaya. Pertama, agama Kristen dilarang menjadi sebuah agama di kekaisaran. Kedua, nama Kristen telah cukup untuk membuktikan alasan menghukum karena pelaku revolusi dan tindakan kriminal. Ketiga, menolak menjalankan hukum yang berlaku di Romawi. [Lihat Dom Charles Poulet, Church History Vol. I (London: Herder Book, 1956), hlm. 66-67].

${ }^{3}$ Dom Charles Poulet, Church History ..., hlm. 66-67.

${ }^{4}$ Gnostisisme merupakan sinkretisme paganisme, kristianisme dan yudaisme dengan gaya filsafat Neoplatonis. Gnostisime ingin menjawab pertanyaan mendasar tentang manusia dan keselamatan: siapa, menjadi apa, dari mana, di mana dibuang, ke mana tujuan, dari mana dibebaskan, apa itu generasi dan regenerasi, sumber kejahatan. Keselamatan tergantung dari pengetahuan. Ada dua tokoh utama aliran gnostisisme, yaitu Basilide dan Valentinus. [Lihat Hubertus R. Drobner, Patrologia ..., hlm. 165-166; C. Groenen, Sejarah Dogma Kristologi: Perkembangan Pemikiran tentang Yesus Kristus pada Umat Kristen (Yogyakarta: Kanisius, 1987), hlm. 87-88; Gerald O’Collins dan Edward G. Farrugia, Kamus Teologi, judul asli A Concise Dictionary of Theology, diterjemahkan oleh I. Suharyo (Yogyakarta: Kanisius, 1996), hlm. 92-93.

${ }^{5}$ Menurut marcionisme, aliran heretik yang dipelopori oleh Marcion, manusia dan dunia ini tidak diciptakan Allah yang baik, melainkan demiurg. Misi Kristus ialah membawa warta dari Allah yang baik, yang tak pernah dikenal oleh manusia, dan yang tidak ada kaitannya dengan dunia. Kristus hanya tampaknya saja mengambil tubuh manusia. Bagi Marcion, Kristus hanyalah pewarta keselamatan. [Lihat Hubertus R. Drobner, Patrologia, hlm. 174175].

${ }^{6}$ Montanisme didirikan oleh Montanus. Bersama murid-muridnya, ia ingin menghidupkan kembali entusiasme perihal parousia dengan menggalakkan puasa, selibat dan kemurnian. Montanisme mengutamakan peranan Roh Kudus dan menentang hirarki dan mengajarkan keselamatan hanya ditujukan bagi orang-orang tertentu saja. [Lihat Hubertus R. Drobner, Patrologia ..., hlm.176-177].

7 Untuk membela kesatuan Allah, monarkianisme mengaburkan otonomi Putera Allah. Monarkianisme tediri dari dua kelompok. Pertama, adopsionisme, yang menyebut bahwa kelahiran dan pertumbuhan Yesus Kristus terjadi seperti manusia biasa, dan dalam pembaptisan, Ia diangkat oleh Allah sebagai Putera. Kedua, patripassianisme atau modalisme yang menyatakan bahwa Bapa dan Putera merupakan dua manifestasi dari Allah yang satu dan yang sama. Bapa, dalam rupa Putera, menderita di kayu salib. Ketika Sabellius membawa ajaran ini ke Roma, aliran ini disebut sabellianisme. [Lihat Hubertus R. Drobner, Patrologia, hlm. 178-179]. 
penetapan rumusan iman Gereja. Untuk mempertahankan ajaran yang ortodoks, Gereja harus menyeleksi ajaran tersebut agar sesuai dengan ajaran iman yang benar dalam kesatuan dengan Gereja universal. ${ }^{8}$

\section{Kristologi Ireneus}

Kristologi Ireneus tidak lepas dari paham tentang Allah. Ireneus menyebut Allah sebagai awal, tidak dijadikan atau diciptakan, tanpa awal dan tanpa akhir ( $A H$ II,34.2; $A H$ III,8.3; $A H$ IV, 38.1). Allah menciptakan segala sesuatu dari yang tidak ada $(A H$ IV,6.2). Dalam diri Allah terdapat kesempurnaan, keabadian, kekuasaan, kebaikan dan kebijaksanaan ( $A H$ IV,38.3; $A H \mathrm{~V}, 17.1)$. Allah adalah universal intelect, cinta, roh, pendengaran, mata, cahaya dan sumber dari segala yang baik ( $A H$ II,13.3). Semua atribut kebesaran Allah ini tidak dapat diukur dan berada di luar jangkauan akal budi manusia ( $A H$ IV,20.1). Ireneus menegaskan bahwa dalam diri Allah terdapat segala sesuatu yang baik, dan Allah bertindak sebagai Allah yang baik (AH III,25.2). Menurut Ireneus, Allah Perjanjian Lama dan Allah Perjanjian Baru adalah Allah yang satu dan yang sama. ${ }^{9}$

Ireneus tidak pernah ragu bahwa hanya ada satu Allah, yaitu Allah Abraham, Allah Ishak dan Allah Yakub, yang adalah pencipta yang tidak dipengaruhi oleh siapa pun. Allah menciptakan segala sesuatu atas dasar kehendak-Nya, bebas dan penuh cinta, sebab Dia transenden dan absolut. Ia menciptakan manusia dengan kedua tangan-Nya. ${ }^{10}$

\footnotetext{
${ }^{8}$ Eddy Kristiyanto, Visi Historis ..., hlm. 40; Philip Scaff (ed.), The Apostolic Fathers with Justin Martyr and Irenaeus (Edinburg: Grand Rapids, 2001), hlm. 510; Alois Grillmeier, Gesù il Cristo ..., hlm. 280-281.

${ }^{9}$ Eric Osborn, Irenaeus of Lyons (Cambridge: Cambridge University Press, 2003), hlm. 28-30.

10 Gagasan tentang 'dua tangan Allah' dikemukakan oleh Theofilus. Dalam menafsirkan Kejadian 1:26 perihal penciptaan manusia, ia mengatakan bahwa Allah menggunakan kedua tangan-Nya, yaitu Logos dan Sophia. Ireneus dengan hati-hati menyamakan kombinasi LogosSophia dengan Putera-Roh (Kudus) atau menjelaskan bahwa Logos-Sophia sama dengan Putera-Roh. Walaupun memuat gagasan yang sama, Ireneus memilih menggunakan kombinasi Putera-Roh (Kudus), sebab memiliki dasar biblis. [Lihat Robert M. Grant, Jesus after the Second Century (London: SCM Press, 1990), hlm. 99-100].
} 


\section{Yesus Kristus, Logos Ilahi}

Pada zaman Ireneus, kristologi-logos menjadi istilah baru untuk menjelaskan Yesus Kristus sebagai Allah Putera yang sejak kekal ada dan yang tetap bersatu dengan Allah Bapa. Kristologi-Logos dimaksudkan untuk menekankan bahwa Yesus Kristus adalah Logos, Putera dan Firman Allah. Putera berbeda tetapi sekaligus bersatu dengan Bapa. ${ }^{11}$

Para apologet memakai ungkapan logos untuk mempertanggungjawabkan iman Kristen di hadapan filsuf kafir sekaligus untuk menangkal ajaran bidaah-bidaah yang membingungkan umat. Merujuk pada prolog Injil Yohanes (Yoh 1:1-3) dan dibantu pemahaman filosofis tentang logos, para apologet menerangkan praeksistensi Yesus Kristus. Pemahaman ini diawali dengan asumsi tentang adanya seorang mediator sekaligus pencipta dunia ini. Mediator itu adalah Logos. Logos yang sejak awal bersama dengan Bapa kemudian menjelma menjadi manusia (Yoh 1:14). ${ }^{12}$

Pemahaman inilah yang dijelaskan oleh Ireneus dalam perjuangannya melawan ajaran kaum Valentinian ${ }^{13}$. Sama seperti para apologet sebelumnya, ia menerangkan peranan Logos sebagai pencipta sekaligus perantara. Menurut Ireneus, Yesus Kristus adalah Logos Ilahi yang bertindak sebagai Firman Allah. Lewat Firman itu, Allah menciptakan segala sesuatu dari yang tidak menjadi ada (creatio ex nihilo). ${ }^{14}$

\footnotetext{
${ }^{11}$ Nico Syukur Dister, Kristologi: Sebuah Sketsa (Kanisius: Yogyakarta, 1987), hlm. 284-285.

12 Wilhelm Bousset, Kyrios Christos, diterjemahkan oleh Jhon E. Steely (New York: Abingdon Press, 1970), hlm. 422; C. Groenen, Sejarah Dogma Kristologi ..., hlm. 101.

${ }^{13}$ Valentinian adalah pengikut Valentinus, yang mendirikan salah satu sekte gnostik terpenting abad II. Valentinus mengajarkan suatu sistem aeon (waktu abadi atau emanasi keilahian) yang rumit. Dengan cara syzigies (kawin), Sofia (dewi perempuan dan salah satu eon yang paling rendah) melahirkan Demiurg, yaitu pencipta dunia, yang diidentifikasi sebagai Allah (yang jahat) Perjanjian Lama. [Lihat Gerald O'Collins dan Edward G.

Farrugia, Kamus Teologi ..., hlm. 347.

${ }^{14}$ Wilhelm Bousset, Kyrios Christos ..., hlm. 422..
} 


\section{Yesus Kristus, Logos yang Berinkarnasi}

Ireneus menekankan pentingnya inkarnasi Logos dalam sejarah keselamatan. Bagi Ireneus, peristiwa inkarnasi merupakan kunci sejarah keselamatan. Dengan inkarnasi Logos, manusia dibebaskan dari dosa dan mencapai kepenuhan (pleroma). ${ }^{15}$ Ireneus memulai ajarannya dengan mengatakan bahwa Allah menciptakan manusia menurut gambar dan rupa Allah. Dalam penciptaan, Allah menanamkan intuisi dalam diri manusia, agar manusia dapat mengenal Allah, dan melalui ciptaan mengetahui bahwa ada satu Tuhan dan Allah yang universal ( $A H$ II,6.1). Hal ini hanya mungkin jika manusia memiliki kehendak yang kuat. Namun, karena dosa manusia pertama, manusia terpisah dari Allah. Agar manusia dapat mengenal dan melihat Allah lagi, Allah harus hadir dalam kehidupan manusia $(A H$ IV, 6.4$) .{ }^{16}$ Melalui kehadiran-Nya di tengahtengah manusia, manusia dapat mengetahui bahwa Allah Bapa yang tidak kelihatan itu adalah Allah yang satu dan merangkum segala sesuatu di dalam diri-Nya. Dalam semua rencana itu, Allah sendirilah yang berinisiatif untuk memperkenalkan diri-Nya ( $A H$ III,24.2; $A H$ IV ,20.1). ${ }^{17}$

Allah ingin mengkomunikasikan cinta-Nya dan menebus dosa manusia. Maksud tersebut diwujudkan dengan mengutus seorang pengantara. Pengantara itu haruslah sungguh Allah dan sungguh manusia. Pengantara itu adalah Yesus Kristus. Dia adalah pengantara Allah bagi manusia agar manusia dapat mengenal dan melihat Allah secara langsung. Ireneus menegaskan hal tersebut dengan mengutip ucapan Yesus yang mengatakan bahwa siapa yang telah melihat Putera, yaitu Yesus Kristus, telah melihat Bapa (lihat. Yoh 14:9, 12:14). Ireneus menjelaskan realitas inkarnasi Yesus Kristus dan historisitas karya penebusan sekaligus menjelaskan identitas Kristus, Allah dan manusia, untuk melawan pandangan dualistis. ${ }^{18}$

Inkarnasi Yesus Kristus adalah medium untuk menebus dosa manusia. Yesus Kristus, satu-satunya Logos dari Allah Bapa, menjadi

\footnotetext{
15 Wilhelm Bousset, Kyrios Christos ..., hlm. 422.

${ }^{16}$ Eric Osborn, Irenaeus of Lyons ..., hlm. 30-32.

${ }^{17}$ Eric Osborn, Irenaeus of Lyons ..., hlm. 30.

${ }_{18}$ Denis Minss, Irenaeus: An Introduction ..., hlm. 51; Alois Grillmeier, Gesù il Cristo nella fede della Chiesa ..., hlm. 281.
} 
manusia agar manusia dapat diangkat menjadi putera Allah. Dengan demikian, manusia dapat mencapai kepenuhan dirinya dan Allah dapat kembali mengkomunikasikan cinta-Nya. Bagi Ireneus, Yesus Kristus adalah Logos dari Allah yang sejak awal telah ada bersama dengan Bapa dan berinkarnasi demi keselamatan manusia ( $A H$ III,16.2). Ireneus menambahkan, "Logos Allah adalah Yesus Kristus, yang menjadi manusia di antara manusia untuk menggabungkan yang terakhir menjadi yang pertama, yakni manusia kepada Tuhan" $(A H \mathrm{IV}, 20.4) .{ }^{19}$

Menurut Ireneus, Logos adalah pemimpin seluruh ciptaan. Kehadiran-Nya merupakan rangkuman dari ciptaan dan kejatuhan Adam ke dalam dosa untuk memperbarui segala ciptaan dan menyelamatkan manusia. Dengan demikian, oleh Yesus Kristus, dunia dengan sejarahnya dibawa ke puncak, yakni kepada Bapa. Kepenuhan dalam Kristus mencakup dunia dan sejarahnya. ${ }^{20}$

Ireneus menyimpulkan pemikirannya tentang inkarnasi dengan mengatakan bahwa Yesus Kristus adalah puncak jawaban Allah agar manusia dapat melihat kehadiran Allah. Sang Putera adalah Bapa yang kelihatan $(A H$ IV,6.6). Dengan inkarnasi, Allah yang tidak kelihatan menjadi Allah yang kelihatan, yang dapat berbicara dan mendengarkan manusia. Kehadiran Allah dalam kehidupan manusia bertujuan untuk mencari ciptaan-Nya dan membawa ciptaan itu kembali ke bahu-Nya $(A H \mathrm{~V}, 15.2) .^{21}$

\section{Recapitulatio}

Ireneus merangkumkan pemikiran kristologinya dengan kata recapitulatio. Kata ini dipakai oleh para apologet pada abad kedua, mulai dari Yustinus Martir dan dipopulerkan oleh Ireneus. Kata ini sudah digunakan oleh Paulus dalam surat-suratnya. Kata recapitulatio memiliki

\footnotetext{
${ }^{19}$ Wilhelm Bousset, Kyrios Christos ..., hlm. 422; Jean Galot, Who is Christ? A Theology of the Incarnation (Roma: Gregorian University Press, 1980), hlm. 220-223; Robert M. Grant, Jesus after the ..., hlm. 101.

${ }^{20}$ Aloys Grillmeier, Christ in Christian Tradition (London: A. R. Mowbray and Co., 1965), hlm. 120.

${ }^{21}$ Denis Minns, Irenaeus: An Introduction ..., hlm. 51; C. Groenen, Sejarah Dogma Kristologi ..., hlm.103.
} 
arti yang luas: penyatuan, pengulangan, penebusan, kesempurnaan, pelantikan, totalitas dan kemenangan Kristus (Christus Victor). Recapitulatio digunakan untuk menjelaskan rangkuman keselamatan yang dimulai oleh Allah Bapa dan berpuncak dalam diri Yesus Kristus. Muatan recapitulatio terkait erat dengan sejarah keselamatan manusia (oikonomia). ${ }^{22}$

Kata recapitulatio berasal dari kata kerja bahasa Yunani anakhephalaiomai dan kata benda kephale atau kepala. Dalam Roma 13:8, Paulus menggunakan kata ini untuk mengartikan kesatuan dalam cinta. Sementara dalam Efesus 1:10, Paulus menggunakannya untuk menjelaskan kesatuan seluruh dunia dalam diri Yesus sebagai Kepala. Recapitulatio mengandung peristiwa saat Kristus menjadi manusia untuk mengembalikan manusia kepada hakikatnya semula agar mengalami kepenuhan (pleroma). Kata ini menjadi rangkuman atas apa yang dilakukan oleh Yesus. Yesus hadir untuk memperbaiki kejatuhan yang dilakukan oleh manusia pertama. Kristus hadir dalam setiap segi kehidupan manusia dan dalam setiap peristiwa keselamatan ( $A H$ III,16.6). Sebagai pencipta, Ia datang kepada ciptaan-Nya $(A H \mathrm{~V}, 18.2)$ dan merangkum segala ciptaan-Nya di dalam diri-Nya sendiri $(A H \mathrm{IV}, 6.2)$. Kehadiran Kristus membawa manusia dari kematian yang disebabkan oleh dosa kepada kehidupan kekal, di mana Kristus sendiri adalah Kepala (AH III,16.6). Sabda yang berinkarnasi menjadi manusia adalah satusatunya jalan yang membawa manusia kepada kehidupan yang kekal. ${ }^{23}$

\section{Yesus Kristus, Adam Kedua}

Ireneus memulai doktrin tentang recapitulatio dengan mengatakan bahwa Yesus Kristus adalah Adam kedua. Yesus Kristus hadir untuk memperbaiki kesalahan yang dilakukan oleh Adam. Dalam Adam pertama, manusia jatuh ke dalam dosa dan kemalangan akibat ketidaktaatan Adam ketika memakan buah di taman Eden. Ketidaktaatan ini mengakibatkan umat manusia berdosa dan kehilangan kemuliaan

22 Eric Osborn, Irenaeus of Lyons ..., hlm. 97-98; Adrianus Sunarko, Kristologi: Timjauan Historis-Sistematike (Jakarta: Obor, 2017), hlm. 71.

${ }^{23}$ Jonathan S. Jones, Irenaeus and Principles of Transcendental Theology (Tenesse: Jackson, 2013), hlm. 14; Eric Osborn, Irenaeus of Lyons ..., hlm. 98. 
selaku gambar Allah. Walaupun jatuh ke dalam dosa, Allah tetap menyertai manusia yang malang itu $(A H \mathrm{~V}, 1.2 ; A H$ III,18.1). Karena cinta-Nya, Allah menyelamatkan dan menebus manusia. Penebusan manusia membutuhkan pribadi yang melampaui manusia yang jatuh ke dalam dosa. Cinta Allah ini berpuncak pada Firman yang menjadi manusia, yaitu Yesus Kristus, yang mesti mengalamai kematian ( $A H$ IV,5.4). Dengan bangkit, Yesus Kristus, Firman yang menjadi manusia, mengalahkan maut dan Iblis. Ia mewujudkan kepenuhan janji keselamatan yang telah dinubuatkan para nabi dan memulai sebuah kehidupan baru bagi manusia. Janji keselamatan itu terpenuhi lewat inkarnasi Yesus Kristus tanpa mengurangi ketuhanan atau kemanusiaanNya. Misteri ini adalah misteri keselamatan umat manusia. ${ }^{24}$

Ireneus menyebut Firman yang menjadi manusia sebagai Adam baru yang memuat dalam diri-Nya seluruh umat manusia dan mengulang dalam eksistensi-Nya seluruh sejarah umat manusia dengan arah terbalik. Dalam Adam, yang tidak taat, umat manusia turun dari keadaan mulia, selaku gambar Allah dan kebakaan, ke dalam keadaan malang yang takluk kepada maut. Dalam Yesus Kristus yang taat, umat manusia diangkat dari keadaan malang yang dikuasai maut dan Iblis menjadi anak Allah, serupa dengan Anak Allah. Kehadiran Yesus Kristus melebihi keadaan awal manusia yang diciptakan secitra dengan Allah. Melalui Yesus Kristus, umat manusia dipersatukan dengan Bapa untuk selamanya dan menang atas setan yang menjatuhkan Adam, manusia pertama ( $A H$ V,36,3). Penebusan yang dilaksanakan oleh Kristus merupakan inisiatif Allah. Dengan kehadiran Yesus, manusia dapat belajar mengenai Tuhan dan dapat mengenal kembali kebenaran yang berasal dari Allah Bapa. Dengan kehadiran Kristus, manusia kembali kepada persahabatan asali dengan Allah dan dilepaskan dari musuh yang menyebabkan manusia mengalami kematian. ${ }^{25}$

Ireneus mengulangi apa yang dijelaskan oleh Paulus dalam Rom 5:12-21. Kehadiran Kristus memperbaiki kejatuhan yang dilakukan oleh Adam dan memulihkan umat manusia. Rekapitulasi menjadi elemen yang

\footnotetext{
${ }^{24}$ Jonathan S. Jones, Irenaeus and Principles ..., hlm. 17-18.

${ }^{25}$ Eric Osborn, Irenaeus of Lyons ..., hlm. 113; C. Groenen, Sejarah Dogma Kristologi ..., hlm. 103.
} 
menyatukan seluruh manusia di bawah Kristus sebagai Kepala ( $A H$ III,16.6.) Allah dan manusia dipersatukan dalam Kristus. Kristus menjadi manusia untuk menyelamatkan manusia yang berdosa. Dia menjadi yang pertama dan yang sulung yang bangkit dari kematian dan membawa manusia kembali kepada kesempurnaan $(A H \mathrm{~V}, 1.3$; $A H \mathrm{III}, 18.7){ }^{26}$

Sebagai manusia, Kristus lebih kuat dari Adam karena Kristus membawa kembali kehidupan manusia yang telah diambil pada saat Adam berdosa $(A H \mathrm{~V}, 21.3)$. Adam pertama adalah pribadi yang tidak taat kepada Tuhan dan memilih berpihak kepada kejahatan. Konsekuensinya ialah manusia jatuh ke dalam dosa dan diusir dari surga. Lewat kehadiran Yesus Kristus sebagai Adam baru, manusia semakin menyadari dirinya sebagai pusat dan puncak dari semua ciptaan dan diangkat kembali menjadi anak Allah. Ketidaktaatan Adam adalah inti dari kejatuhan manusia, ketaatan Yesus Kristus adalah inti karya penebusan Kristus. Kristus adalah Allah dan manusia yang membebaskan manusia dari ikatan kejahatan dan mengembalikan kehidupan manusia ke kehidupan awal, yakni kehidupan yang bebas dalam kepatuhan. Kematian telah ditebus dengan kebangkitan Yesus Kristus. ${ }^{27}$

\section{Yesus Kristus, Allah yang Melintasi Sejarah Penyelamatan (Oikonomia)}

Oikonomia dapat diartikan sebagai keselamatan yang dilaksanakan oleh Allah lewat sejarah hidup manusia. Dalam literatur Yunani, kata ini diartikan sebagai pengaturan yang disengaja. Paulus menghubungkannya dengan karya Yang Ilahi untuk keselamatan manusia (bdk. Ef 1:9-12) dan realisasinya lewat perantaraan wahyu Allah (bdk. Ef 3:2-11). Bagi Ireneus, Allah adalah arsitek bijaksana atas segala ciptaan. Ia melanjutkan karya-Nya dalam sejarah keselamatan manusia. Yesus menunjukkan keindahan atas karya karya penyelamatan yang dilaksanakan oleh Allah. Keindahan itu dimulai dengan menciptakan

\footnotetext{
${ }^{26}$ Eric Osborn, Irenaeus of Lyons ..., hlm. 111-112.

${ }^{27}$ Jonathan S. Jones, Irenaeus and Principles ..., hlm. 18.
} 
dunia. Namun, karya Allah tidak berhenti di sini. Ia melanjutkan karyaNya dalam peristiwa-peristiwa yang dialami ciptaan-Nya. ${ }^{28}$

Karya Allah itu berpuncak dalam diri Yesus Kristus, Tuhan yang menjadi manusia untuk mengangkat manusia menjadi anak angkat Allah. Kristus menjadi Adam kedua. Inkarnasi menjadi kunci untuk memperbaiki ekonomi keselamatan yang dirusak oleh Adam. Kehadiran Allah itu tidak terbatas pada inkarnasi, namun nyata sepanjang sejarah keselamatan. Seluruh ekonomi keselamatan adalah rencana Allah. Perjanjian Lama dan Perjanjian Baru menampilkan rencana universal Tuhan untuk membawa manusia kepada keselamatan dan berkat. ${ }^{29}$

Ireneus memaknai oikonomia sebagai tindakan produktif Allah, entitas terstruktur, pengaturan peristiwa, dan tujuan setiap peristiwa. Ireneus menggunakan kata ini sebanyak duapuluh tujuh kali. Kata ini ia artikan sebagai rangkuman ciptaan. Dalam arti sempit kata ini mengacu pada inkarnasi dan dalam arti luas kata ini dapat berarti manifestasi yang dilakukan oleh Allah dalam diri Yesus Kristus. Allah ingin membagikan hidup-Nya kepada manusia. Oikonomia berarti sejarah keselamatan yang diwakili dan dimulai oleh Adam sebagai manusia ( $A H$ IV,33.15). ${ }^{30}$

Dalam tanggapannya melawan gnosi Valentinian, Ireneus merumuskan ajarannya dengan mengatakan bahwa oikonomia berarti penyelamatan Allah sejak awal mula. Penyelamatan Allah ini dilanjutkan dengan panggilan Israel. Sejarah ini disempurnakan dalam kematian dan kebangkitan Kristus serta panggilan keselamatan kepada semua orang, bukan hanya orang Yahudi. Konsep ini diperoleh Ireneus dari gurunya Policarpus sekaligus menanggapi antusiasme umat akan parousia pada zaman itu. Ireneus melihat oikonomia sebagai persatuan kembali penciptaan dunia sejak awal dunia dan menempatkan Kristus di tengah. Penciptaan, inkarnasi Kristus, keselamatan dan kebangkitan adalah sebuah kesatuan yang tak terpisahkan dalam rencana penyelamatan manusia. $^{31}$

\footnotetext{
${ }^{28}$ Eric Osborn, Irenaeus of Lyons ..., hlm. 74-76.

${ }^{29}$ Eric Osborn, Irenaeus of Lyons ..., hlm. 76-77.

${ }^{30}$ Eric Osborn, Irenaeus of Lyons ..., hlm. 77-80.

31 Joseph Trigg, "The Apostolic Fathers and Apologists", dalam Alan J. Hauser dan Duane F. Watson (ed.), A History of Biblical Interpretation Vol. I (Michigan: Wiliam B. Eermans
} 


\section{Yesus Kristus, Pemersatu Seluruh Ciptaan (Anakephalesthai)}

Ketaatan Kristus yang membuat-Nya wafat di kayu salib menjadikan manusia yang percaya kepada Yesus Kristus tidak lagi berada di bawah kekuasaan setan, melainkan kekuasaan Tuhan ( $A H$ III,12.9). Dengan kebangkitan-Nya, Yesus Kristus mempersatukan orang yang percaya kepada-Nya. ( $A H$ III,19.3). Yesus Kristus memberikan tubuh-Nya dan mencurahkan Roh Kudus kepada kita. Dia mempersatukan kembali manusia ke dalam persekutuan dengan Allah di dalam tubuh-Nya. ( $A H \mathrm{~V}, 1.1)$. Kehadiran Yesus Kristus di dunia adalah kehadiran seorang manusia yang tidak berdosa $(A H \mathrm{IV}, 44.2)$ dan dengan kebangkitan-Nya, Dia dapat dilihat sebagai Allah. Lewat kebangkitan ini, manusia ditebus oleh Tuhan. ${ }^{32}$ Tujuan kehadiran Yesus ialah mempersatukan seluruh ciptaan ke dalam diri-Nya. Penyelamatan universal itu terjadi melalui persatuan manusia dan Allah dalam diri Yesus. Untuk menekankan persatuan manusia dan Tuhan dalam diri Yesus, Ireneus menggunakan terminologi commixtio. ${ }^{33}$

\section{Yesus Kristus, Sungguh Allah dan Sungguh Manusia}

Kristologi Ireneus adalah sebuah kristologi yang bersifat soteriologis. Kehadiran Kristus adalah kehadiran yang menyelamatkan umat manusia. Ia melihat bahwa jika Logos Allah datang ke bumi untuk menyelamatkan umat manusia, maka Logos itu harus memiliki kedua kodrat yakni ilahi dan manusiawi (vere homo vere deus) ${ }^{34}$. Ireneus menegaskan bahwa Yesus adalah manusia. Dalam pengakuannya, ia melihat bahwa kemanusiaan Yesus adalah sebuah nilai kebaikan yang sangat dalam. Ide penyelamatan hanya terjadi jika Kristus sungguhsungguh manusia. Dengan kehadiran-Nya, kemanusiaan setiap orang

Publishing Company, [tanpa tahun terbit]), hlm. 328; Aloys Grillmeier, Christ in Christian ..., hlm. 119.

32 Eric Osborn, Irenaeus of Lyons ..., hlm. 121-123.

${ }^{33}$ Anthony Briggman, Ireneus' Christolgy of Mixture, https://www.academia.edu/35023148/ Irenaeus_Christology_of_Mixture, diakses pada 7 Desember 2019, hlm. 46-49.

${ }^{34}$ Ireneus menyebut Yesus Kristus sebagai sungguh Allah dan sungguh manusia sebanyak tiga kali. Pertama, Jesus Christus vere homo vere Deus (AH IV,6.7). Kedua, Verbum potens et homo verus $(A H \mathrm{~V}, 1.1)$ dan ketiga, quoniam homo et quoniam Deus $(A H \mathrm{~V}, 173)$. [Lihat Wilhelm Bousset, Kyrios Christos ..., hlm. 421.] 
bukan lagi bersifat temporal melainkan kekal. Dengan menjadi manusia, Yesus dapat bersatu dengan manusia. Pemikiran Ireneus ini didasarkannya pada prolog Injil Yohanes tentang Yesus, "Sabda Tuhan telah menjadi daging". Dengan itu, Ireneus meyakini bahwa Yesus Kristus adalah sungguh Allah dan sungguh manusia. ${ }^{35}$

\section{Kesimpulan}

Dalam kristologi sekaitan dengan konsep penebusan, Ireneus, uskup Lyon, menyebut Yesus Kristus sebagai Adam kedua. Yesus Kristus merangkum manusia dalam diri-Nya dan menjadi pemersatu seluruh ciptaan. Yesus Kristus sungguh Allah dan sungguh manusia. Melalui inkarnasi, Firman menjadi manusia, rencana penyelamatan Allah untuk manusia terpenuhi dalam diri Yesus, melalui wafat dan kebangkitan-Nya. Seluruh ciptaan ditebus dan dipersatukan dalam diri Yesus Kristus. Gagasan ini dirumuskan dengan kata recapitulatio. Karena sumbangan pemikirannya yang cemerlang, tidak heran bila Ireneus digelari teolog sistematis dan Bapa teologi dogmatis pertama.

Dengan kata recapitulatio, Ireneus membela kebenaran iman Kristen yang terancam akibat ajaran-ajaran palsu yang muncul di tengah Gereja. Ireneus hendak menegaskan bahwa inkarnasi Yesus bertujuan untuk mengangkat manusia menjadi anak Allah. Ireneus mengaitkan antara Allah, ciptaan, manusia dan keselamatan dalam suatu kerangka pengajaran doktrinal yang ortodoks. Beberapa ahli berpendapat bahwa tidak ada Bapa Gereja yang lebih cemerlang dari Ireneus dalam merumuskan pokok pemikiran tentang Allah, manusia dan sejarah keselamatan. ${ }^{36}$ Ireneus berhasil mencapai rumusan iman Gereja secara gemilang. Kegemilangan itu tampak dalam tulisan Bapa-bapa Gereja selanjutnya, yang mengaitkan pemikiran dan ajaran mereka dengan apa yang diajarkan oleh Ireneus. Dengan adanya rumusan iman ini, pemikiran Ireneus ini menjadi sumber inspirasi bagi bapa-bapa Gereja selanjutnya,

\footnotetext{
35 Wilhelm Bousset, Kyrios Christos ..., hlm. 434.

${ }^{36}$ Irenaeus M. C. Steenberg, "The Image of God in Irenaeus, Marcellus and Eustathius", dalam Paul Foster- Sarah Parvis (ed.), Irenaeus: Life, Scripture, Legacy (Minneapolis: Fortress Press, 2012), hlm. 200.
} 
seperti Tertullianus, Athanasius bahkan Agustinus dari Hippo, dalam merumuskan pemikiran seputar topik yang sama.

$$
===0000====
$$




\section{DAFTAR PUSTAKA}

Bousset, Wilhelm Kyrios Christos. Diterjemahkan oleh Jhon E. Steely. New York: Abingdon Press, 1970.

Dister, Nico Syukur. Kristologi: Sebuah Sketsa. Kanisius: Yogyakarta, 1987.

Dister, Niko Syukur. Teologi Sistematika 1: Allah Penyelamat. Yogyakarta: Kanisius, 2015.

Drobner, Hubertus R. Patrologia. Judul asli Lehrbuch der Patrologia, diterjemahkan oleh Paolo Stefano dan Francesco Sirleto. Casale Monferrato: Edizione Piemme, 1998.

Galot, Jean. Who is Christ? A Theology of the Incarnation. Roma: Gregorian University Press, 1980.

Grant, Robert M. Jesus after the Second Century. London: SCM Press, 1990.

Grant, Robert M. Ireneus of Lyons. London: Routledge, 1997.

Grillmeier, Aloys. Christ in Christian Tradition. London: A. R. Mowbray and Co., 1965.

Grillmeier, Alois. Gesù il Cristo nella fede della Chiesa vol. 1. (Judul asli Jesus der Christus im Glauben der Kirche, diterjemahkan oleh Enrico Norelli e Samuele Olivieri. Brescia: Paideia Editrice, 1982.

Groenen, C. Sejarah Dogma Kristologi: Perkembangan Pemikiran tentang Yesus Kristus pada Umat Kristen. Yogyakarta: Kanisius, 1988.

Jones, Jonathan S. Irenaeus and Principles of Transcendental Theology. Tenesse: Jackson, 2013. 
Kristiyanto, Eddy. Gagasan yang menjadi Peristiwa. Yogyakarta: Kanisius, 2002.

Marjanen Antti dan Petri Luomanen (ed.). A Companion to SecondCentury Christian Heretics. Boston: Brill, 2005.

O’Collins, Gerald dan Edward G. Farrugia. Kamus Teologi. Judul asli A Concise Dictionary of Theology, diterjemahkan oleh I. Suharyo. Yogyakarta: Kanisius, 2000.

Orbe, Antonio. "Irenaeus" dalam Angelo Di Bernardino (ed.). "Iraeneus" dalam Encyclopedia of the Early Church. Cambridge: Jame Clarke and Co., 1992, hlm. 413-416.

Osborn, Eric. Irenaeus of Lyons. Cambridge: Cambridge University Press, 2003.

Philip, Scaff (ed.) The Apostolic Fathers with Justin Martyr and Irenaeus. Edinburg: Grand Rapids, 2001.

Poulet, Dom Charles. Church History Vol. I. London: Herder Book, 1956.

Quasten, Johannes. Patrology Vol. I. Notre Dame: Christian Classics, 1960.

Steenberg, Irenaeus M. C, "The Image of God in Irenaeus, Marcellus and Eustathius", dalam Paul Foster- Sarah Parvis (ed.), Irenaeus: Life, Scripture, Legacy. Minneapolis: Fortress Press, 2012.

Sunarko, Adrianus. Kristologi: Tinjauan Historis-Sistematik. Jakarta: Obor, 2017.

Trigg, Joseph. "The Apostolic Fathers and Apologists", dalam Alan J. Hauser dan Duane F. Watson (ed.), A History of Biblical Interpretation Vol. I. Michigan: Wiliam B. Eermans Publishing Company, [tanpa tahun terbit]). 


\section{Sumber Internet}

Briggman, Anthony. Ireneus' Christolgy of Mixture, https://www.academia.edu/35023148/ Irenaeus_Christology_of_Mixture , diakses pada 7 Desember 2019, hlm. 46-49 